\title{
Best Practice Focused Occupationally-Directed Education, Training and Development Practice Prospects Linked to Workplace E-learning
}

\author{
https://doi.org/10.3991/ijac.v11i2.9140 \\ Cindy Londt ${ }^{1}$ and Lize Moldenhauer ${ }^{1}$ \\ ${ }^{1}$ OMNI Academy for Education, Training and Development, Cape Town, South Africa
}

\begin{abstract}
Currently, South Africa offers learning that is credit bearing and directly linked to workplace based learning programs and qualifications. However, e-learning in South Africa is under-developed, and information is not readily available on how universities and colleges are dealing with the advent of e-learning, and how it is linked to occupational learning based qualifications.
\end{abstract}

Learning has changed over the years, but it is assumed that the e-learning model is aimed at people who are technologically more knowledgeable, and who wish to interact electronically with the learning experience.

Considering the various challenges linked to all types of learning, providing critical research on the success of implementing an e-learning approach is required. In addition to this, it is necessary to identify the efficacy of such a model in specific industries.

Challenges are identified but not limited to:

a) The profile of the learner

b) Computer literacy of learners

c) Socio-economic status of learners

d) Collecting evidence from workplace

e) Learner motivation and its management

Occupationally Directed Education Training and Development Practice is an innovative opportunity to create e-learning opportunities that are contextualized to industry specific needs. In addition to this, e-learning is no longer linked to a computer but all forms of devices that enable user interaction. Enabling learning to be shared through phones and tablets provides continuous opportunities for improvement of education and access to such education.

In response to these needs, the e-learning model will attempt to offer learners support specifically for those in an industry where there are time constraints.

This research attempts to clarify the debates that industry and academia are engaged with surrounding the efficacy of e-learning and how to create opportunities that are linked to the socio-economic status of a country. Furthermore, it provides a practical analysis of a learning intervention in which skills and knowledge are conventionally passed through workplace-based specific e-learning opportunities.

\section{INTRODUCTION}

Information technology is becoming an essential part of society, and is being utilised within various sectors, most notably education and within the workplace. The use of technology within these contexts allows for a competitive and efficient scope. This, in turn, facilitates the participation of a much broader sector within education. It is therefore necessary to adapt and enhance skills to become involved within this process of societal change that is circumscribed by technology. By incorporating elearning and work integrated learning (WIL) the service delivery encompassed is challenging traditional instructional delivery of education that has been utilised by tertiary institutions for a long time [5], [1]. E-learning is found in every part of the world, and as such is palpable within skills development beyond that of the classroom. Additionally, the use of technology involves those who are unable to accommodate certain expectations of a contemporary student or employee and as such, opens a path for larger diversity and inclusion [2]. This paper discusses findings that resulted from the data triangulation of a small focus group's interpretation on current, future, and perceived e-learning compared to m-learning. The initial findings present the participants perceptions, credibility, and the perceptions of the quality of the platform.

\section{LITERATURE REVIEW}

The role of work integrated learning, and more specifically, opportunities to link the workplace to learning, have been debated and noted as current challenges from 2002 in higher education in South Africa. This literature review considers work integrated learning theory, practice and framework, as well as the positive and negative impact associated with it. It also examines how elearning based work integrated learning is considered and its distinct perception and applications in South Africa.

Bender [3] notes that the need to link learning to relevance in a consideration of the role of universities and workplace must, "seek ways to be more relevant, to bring their knowledge base to bear on social, cultural and economic problems, and to offer leadership in society consistent with their core values of openness, integrity and inclusion".

\section{A. WIL learning theory, concept and framework}

WIL is the integration of the requirements for the educational programs and the workplace expectations; which is an important framework in that there is an expanding disparity between a student's employment readiness, generic skills, and the expectations that are 
required within industry [7]. Engelbrecht [6] states that higher-order learning is necessary, which can be accomplished through e-learning, which in turn allows learners to become accountable for their own learning. Project oriented learning, a principle of engagement theory, is classified as an instructional framework through which exposure and managing authentic problems is incorporated into learning [5]. Daemonse [5] thus indicates that the manner in which South African learners will become competitive and efficient within industry is the adoption technology into the education domain.

\section{B. WIL and positive and negative impact}

An advantage of the WIL is clear prospectus on employment opportunities indicating a strong link between WIL and generic skills [7]. The identified benefits of utilising WIL e-learning also accommodates staff, parents/guardians, and other interested persons in surrounding communities that do not have access to the immediate institutions geographical location [2]. The technological trend is being adopted by both developed and developing countries. This allows for the holistic transformation of education. Additionally, Barker et al. [2] states that there are various uses for different technologies within a platform to create more convenience for the user. This impacts motivation, showing an increase in autonomy and enthusiasm in the learning process [2]. Furthermore, aligning with the principles of WIL programs, Jackson [10] identifies that on-the-job training aided the students in understanding the application of technology within their fields.

However, Senge et al. [13] identifies that initiation would be a primary challenge within e-learning. In contrast, Barker et al. [2] indicates that potential barriers are present, but do not impact the learning process drastically. It is noteworthy in this respect that aspects such as the screen size, charging devices, and the cost of software are potential barriers. Barker et al. [2] and Sife et al. [14] stress the need for educator training as a necessity, as well as accessing support and synchronicity of various devices. Freudenberg et al. [7] shows that there is a criticism with WIL e-learning as to whether tertiary institutions would have the capability and commitment of being able to fund and continue the process of WIL elearning. Overton and Hills however, stress that the costs involved have clear value and are justified due to the efficiency of utilising technology, time-efficiency, and improvements across the learning process [12].

\section{WIL e-learning}

The combination of WIL and e-learning has indicated positive responses, such as job readiness and motivation [7], [2]. South Africa's job market is expanding and becoming largely a technological environment [8]. As such, WIL e-learning could equip students with more attractive skills for employers [8]. Therefore, for any institution to become more competitive, the incorporation of WIL e-learning is imperative as WIL e-learning is becoming a large resource for both educational institutions and the workplace [8].

\section{WIL e-learning South Africa}

e-learning within South Africa is identified as a positive aspect because of the versatility and flexibility with interactive learning, therefore indicating that WIL elearning can be useful with students with varying backgrounds. Brown [4] contrasts between first and third world learners who have access to mobile devices and identifies both as ideal for the m-learning target markets. Moreover, by incorporating WIL e-learning into curricula, the individual will be able to learn skills that will better equip them within countries and workplaces contextualized by the rapid growth of technology. E-learning is a platform that can aid individuals to study from remote areas by utilising technology such as the internet, thus allowing for broader education and increasing diversity [5], [3]. However, the South African government is restrained by socio-economic problems and may struggle to implement the requirements pertaining to e-learning.

The success of WIL e-learning also depends on the educator's ability to integrate mobile technologies and contemporary learning into a pedagogical framework [4]. The role of enforcing WIL e-learning into South African education also needs to consider the communities and the wealth of knowledge that is found beyond the classroom. Thus, service-learning aligns with the South African curriculum national goals, involving local communities [9]. The learner should be equipped with abilities to discover and evaluate information and applying this into their existing knowledge [4]. The role of e-learning in South Africa is not only to afford access to learners but also to expand the infrastructure for information and communications technology which in turn would enable South Africans to access technologies readily [4], [15].

\section{RESEARCH METHODOLOGY}

The research was undertaken using both qualitative as well as quantitative methods which produced both a theoretical interrogation as well as practical outcomes that were defined and measurable. Qualitative research into the model helped to define the quantitative research required of the more statistical data.

The initial phase of the research included a literature survey to consider current practice used both nationally and internationally. Findings from this research were then considered for selection of the most appropriate models for evaluating e-learning and m-learning perceptions and credibility.

Following this, qualitative research was conducted using small focus groups (internal stakeholders and the project management team). This qualitative research focuses on current, future and perceived interpretation of e-learning versus m-learning; outlining an interest in meaning, perspective and understanding; focusing on process; and combining inductive analysis with grounded theory.

The standard methods of qualitative research were applied, which included: observation, interviews, sampling and written material. Due to the nature of the research problem and key outcomes indicated, a limited range of expert participants were able to provide the bulk of relevant high level inputs.

Data was then reviewed based on key outcomes noted for research purposes and collected through evaluation of survey data completed through large platforms in South Africa in which occupationally directed education, training and development practitioners participate.

A range of inputs was solicited from key experts as indicated above. All participants were voluntary, and were advised both in writing and verbally that their informed consent to participate would be required and that each participant was free to withdraw from participation. 
Confidentiality and anonymity were offered to all participants and maintained through the use of a coded database. However, due to the nature and purpose of this research, as well as the methodology, most participants did not use this option. Data was analysed through data extracted from a database.

In order to enhance the credibility of this research, every attempt was made to identify, encourage and support the participation of key stakeholders and experts. Wherever possible organisational support and input were sought, and where necessary appropriate alternative individuals and/or organisations were identified and approached.

Independent checks were put into place in which data was cross-referenced and audited to ensure that all findings produced were error free.

The findings noted are presented and the analysis of the data according to the categories of data field are shared.

50 participants were invited to participate in the survey. This was based on subject matter experts in the field of workplace integrated learning and occupationally directed education, training and development practice. This was controlled in part.

\section{INITIAL FINDINGS}

\section{A. Participant perceptions of e-learning and m-learning}

The first area of research questions provided the learning specialization areas, work specific sector based learning as well as instances to validate the interaction with types of platforms - namely e-learning vs m-learning.

Participants were from multiple focal areas in terms of the learning specializations - the majority of participants were from credit bearing occupationally directed, education, training and development practice $(62 \%)$ as well as higher education (32\%). Only $6 \%$ of the participants were from non-accredited learning. This helps to formalize the requirements of quality assessment and moderation practice associated with the instruments and resources used in the assessment process.

Specifically, those in occupationally directed education, training and development practice saw themselves aligned to the following sectors:

Education, Service, Emergency Medical Services, Media and Retail Administration. This helps to show the various sectors influenced by credit oriented learning.

\section{Do you, or have you, participated in e-learning (internet based)?}

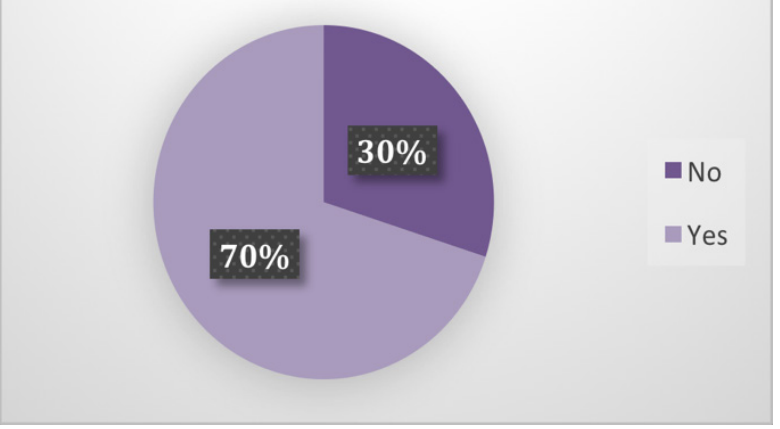

Figure 1.
Figure 1 shows that $70 \%$ of participants had participated in e-learning. This shows that the platform has been explored by the majority of participants - specifically through systems with internet access. This helps to focus on the different platforms linked to electronic learning.

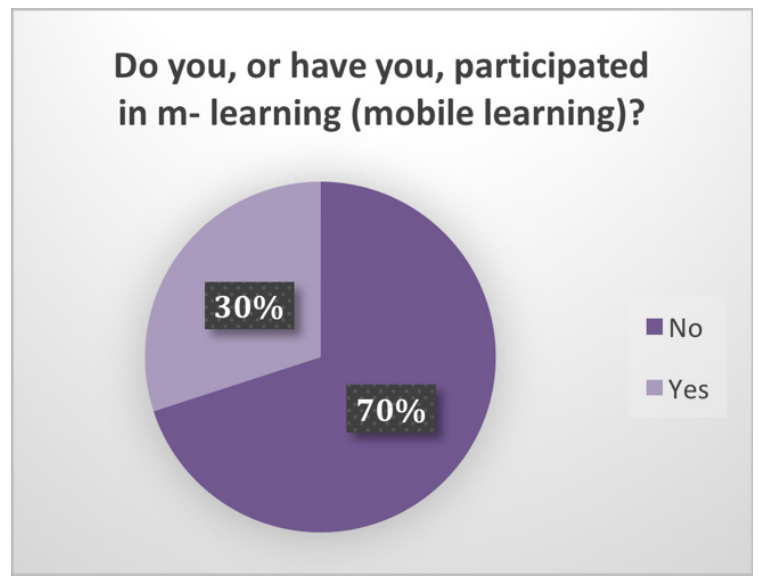

Figure 2.

From figure 2 , it is shown that only $30 \%$ of participants had participated in m-learning. This shows the large difference in engagement with different types of platforms offered through devices, and more specifically a mobile platform or phone which is part of electronic learning.

Seven criteria were identified and ranked in order from the most challenging to the least challenging.

1 - The educational organizations staff resources ability and motivation to engage with learners through a mobile platform was the biggest challenge. This indicates their ability to use the mobile platform, which could be in a personal capacity, with all learners.

The following two challenges were noted as a tie-

2 - The financial resources of an educational organization to set up, design and maintain a mobile platform.

2- The user friendliness of the mobile platform.

The mobile platform which is not the personal capacity of a staff member is reinforced as a challenge.

4 - The security and privacy settings of the organizations IT infrastructure is noted as a secondary reinforcement of the challenge as these are not linked to finances and resources but how the technical system is setup.

5 - My own access to resources is seen as being partially important but if this was primary would have been placed in the top 4 (not 5 as it is).

6 - My own preference in learning style is seen as not being that important and implies that participants feel comfortable with the use of a mobile learning device.

7 - My motivation and comfort levels to participate in mobile learning is seen as the least important, which helps to validate that there is a desire to participate and that participants feel comfortable with using a mobile learning device. 


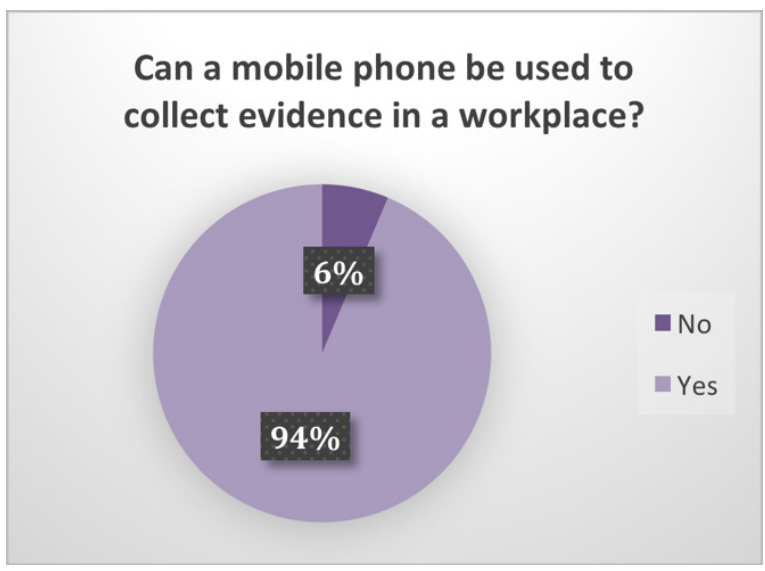

Figure 3.

It is important to note in figure 3 that even though only $30 \%$ of the participants had participated in m-learning that this does not influence the perceptions of the credibility of using mobile phones to collect evidence in a workplace. $94 \%$ of participants were comfortable with the collection of workplace evidence using a mobile phone. This is a significant trust in the platform itself.

\section{B. Credibility of m-learning}

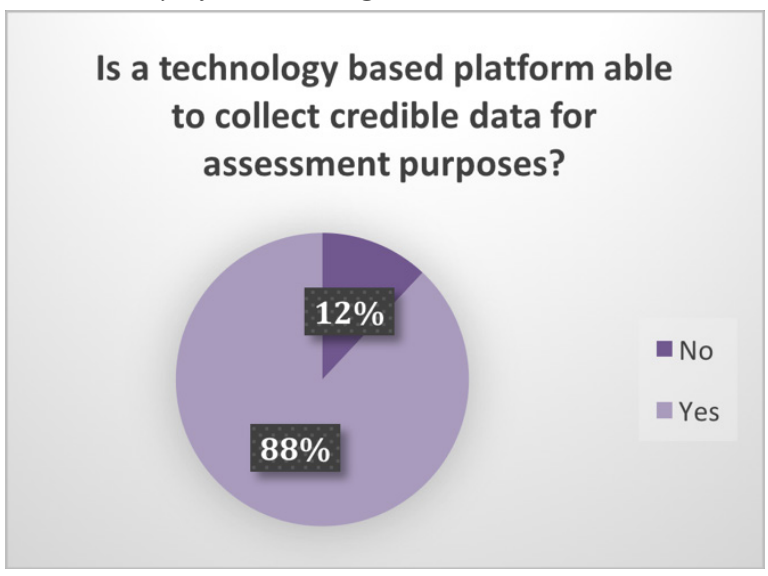

Figure 4.

Similarly, figure 4 shows that $88 \%$ of respondents noted trust in the use of a mobile phone, to collect credible data for assessment purposes. This reinforces the idea that the actual instrument itself is validated. This is the overview statement linked to the platform and the credibility of the data collected therein. This is further interpreted based on the types of data collection opportunities and perceptions thereof which still indicate $12 \%$ believing the credibility element of the platform.

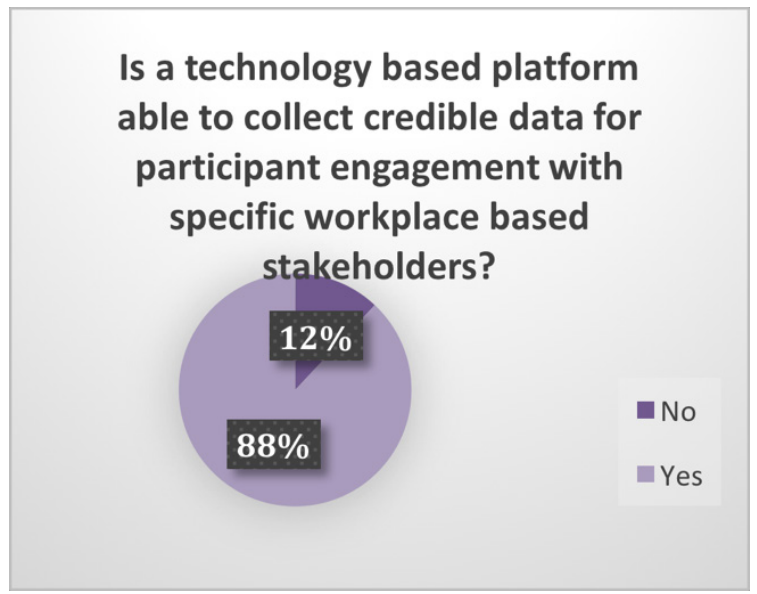

Figure 5.

The same findings are noted in figure 5 for the engagement with the participant using the platform and workplace based stakeholders. The interaction indicates that the engagement between the two parties produces evidence and that this engagement or record thereof is what provides the credible data. $88 \%$ of respondents trust that the evidence produced from this engagement is credible data and only $12 \%$ believe that it is not.

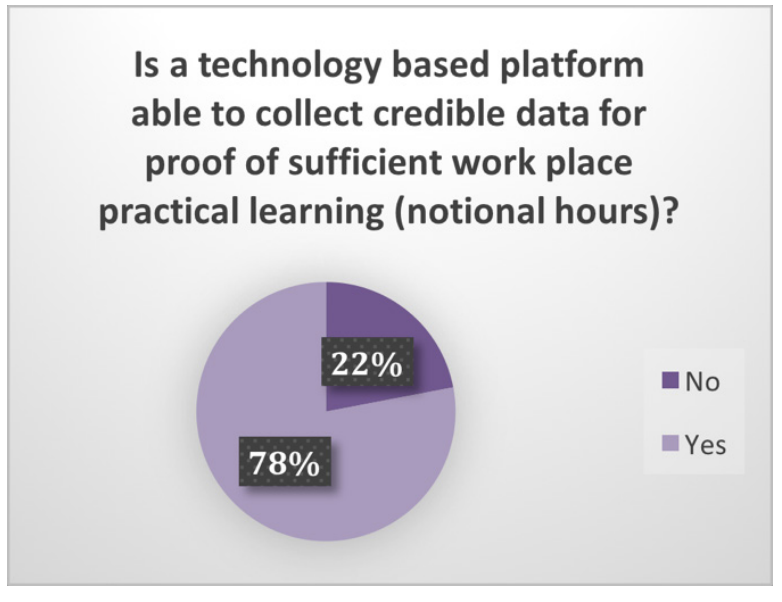

Figure 6 .

Figure 6 indicates that only $78 \%$ of participants believe that credible data can be provided to demonstrate the workplace practical learning component. A larger $22 \%$ felt that this could not be seen as credible data. Comments provided were on how to trust the source of the data and validate that the person had interacted continuously to demonstrate the work integrated learning component. This is noted through comments like, "Depends largely on trusted source" (participant 50) and "As long as the source is credible" (participant 9). This implies that there needs to be a specific means in which to validate this source. 


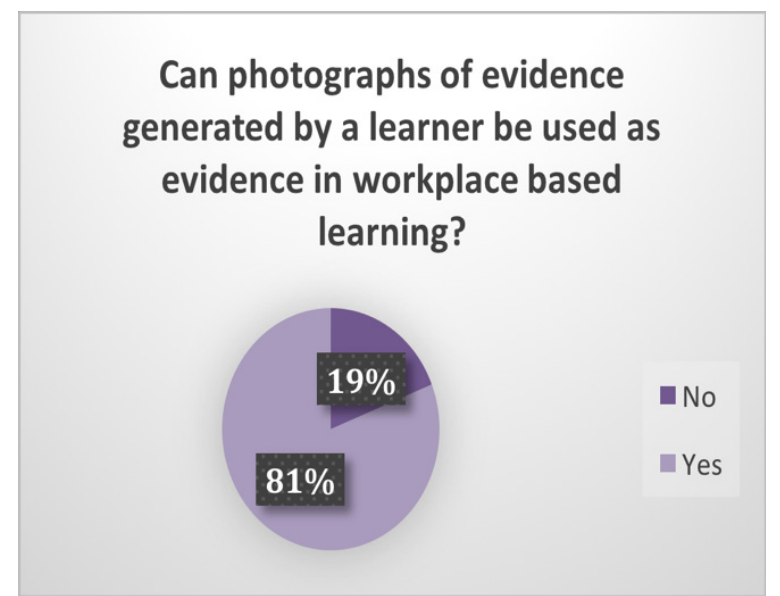

Figure 7.

In figure 7, it is clearly illustrated that $81 \%$ of participants agreed that photographic evidence generated in a workplace can be used for evidence and $19 \%$ do not. This implies that there is some trust linked to photographic evidence. The type of evidence like a photograph in comparison to a video (which requires more electronic storage space, and is the most authentic) is still seen as credible.

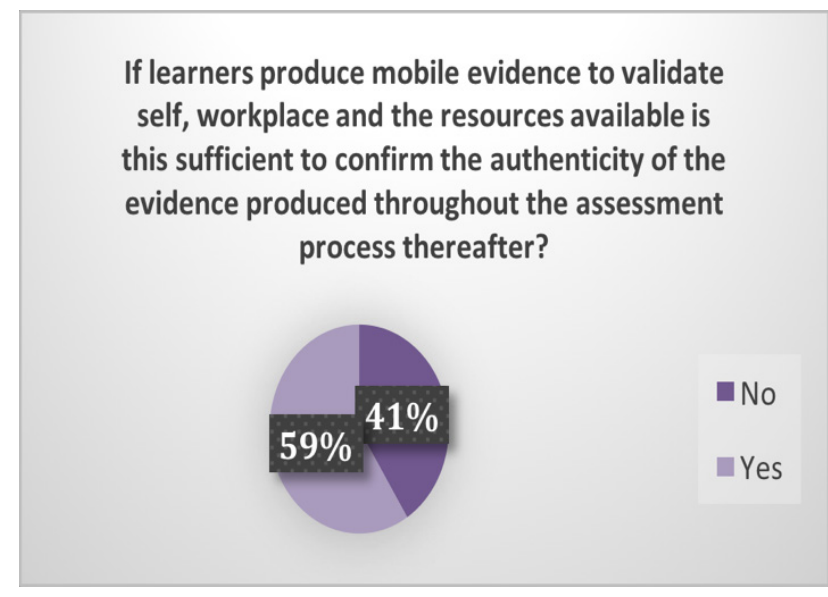

Figure 8.

The greatest challenge noted lies in evidence that validates self, the workplace and resources available from a sufficiency perspective. From figure 8 it can be seen that $59 \%$ of participants believe mobile evidence is able to provide sufficient and credible evidence, therefore $41 \%$ believe it would not. Evidence has to be evaluated by assessors, however, when this evidence is partial, it becomes problematic. Additionally, evidence which cannot be validated and evidence without context are also problematic.

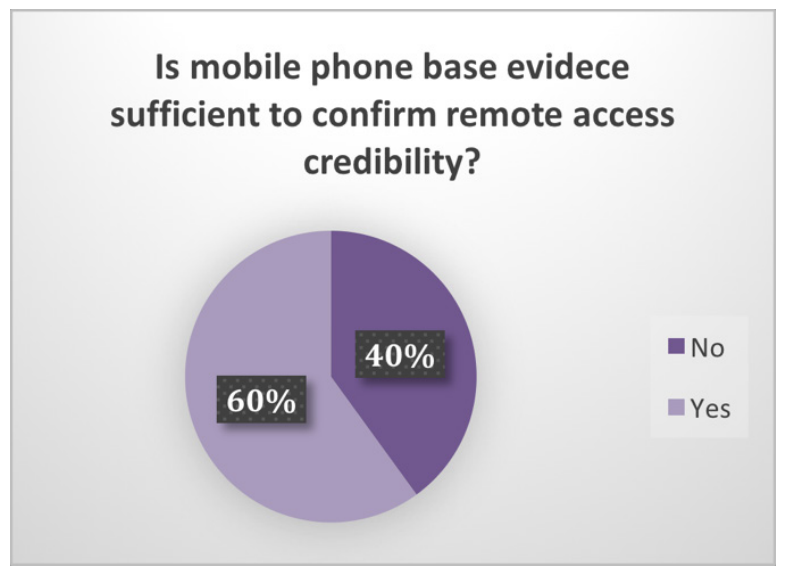

Figure 9

The second challenge noted is the confirmation of credibility of remote access. Figure 9 indicates $60 \%$ of the participants indicated that mobile phone based evidence is sufficient to confirm remote access credibility, while $40 \%$ indicated the opposite. This implies that remote evidence has to be validated in order for its credibility to be considered.

C. Perceptions of quality of platform (e-learning and $m$ learning)

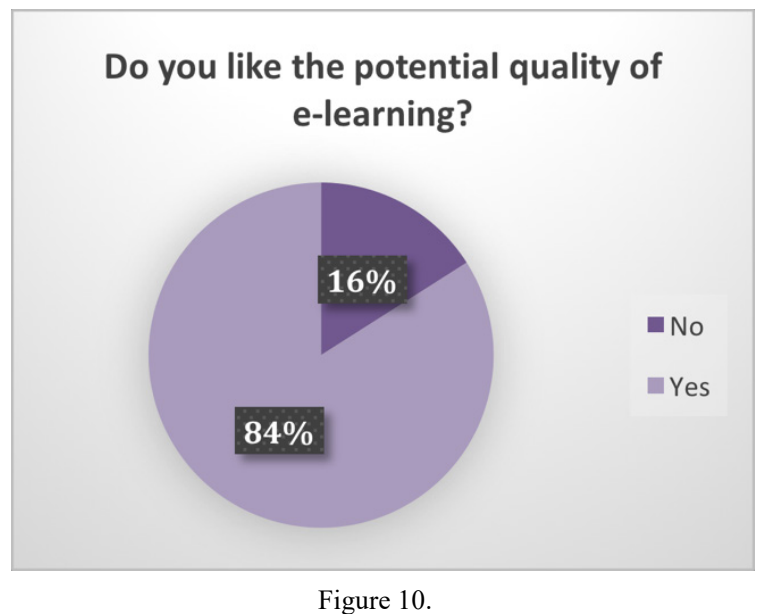

In figure 10 , it can be seen that perceptions of the platform are noted as being $84 \%$ who like the potential of e-learning or computer based learning. This is in contrast to the perceptions of m-learning in which only $76 \%$ like the potential quality. 


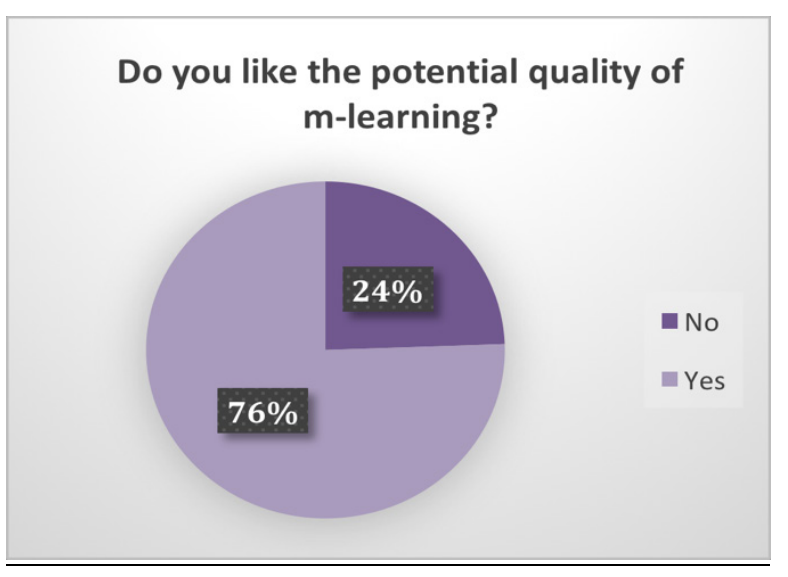

Figure 11.

Finally, in figure 11 it is noted that $24 \%$ of participants did not like the potential quality of m-learning versus the $16 \%$ did not like the potential quality of e-learning. This indicates the challenges that are noted in terms of the link of quality to the platform and how this needs to be further explored.

\section{RECOMMENDATIONS}

One of the critical requirements is an outline of what $\mathrm{m}$ learning evidence should be in part. The following are identified as to how the process of authentication can validate it:

-Encourage government funded projects to initiate mlearning models and implementation in the general, further and higher education areas of learning.

-Encourage engagement with cell phone companies to provide funding towards m-learning models and implementation in the general, further and higher education areas of learning.

- Ongoing research in the area of the quality of $\mathrm{m}$ learning in both the delivery of learning as well as the assessment process.

\section{CONCLUSION}

Although this is an initial research project, it will be ongoing in order to evaluate the perceptions of e/mlearning. The research indicates that the challenge is not the platform but perceptions about the platform.

$\mathrm{m}$-learning provides the opportunity for learning and collection of naturally occurring evidence to take place in the workplace even in remote areas within countries like South Africa.

e-learning has a large, untapped potential in education in how it is designed and implemented. Additionally, the service delivery of education can increase the potential for having education become more inclusive and diverse (Damoense, 2003). The inclusion thereof will allow for a more efficient platform through which competent and skilled persons can be trained. The involvement of WIL and e-learning combines the traditional understanding of education, but incorporates a broader sector of knowledge that will enable a larger portion of individuals to participate within the workplace, as well as become more competitive. This paper identified that a larger portion of the sample population support the involvement of elearning into education, and that there is a support for elearning and m-learning. There is, however, a small portion of participants who questioned the credibility of data collection through the use of technology based platforms, which can add to the disadvantages of WIL e-learning. Despite this, there appears to be firm support from literature and the participants within this study to affirm that e-learning has a future in education, especially within the South African context.

\section{REFERENCES}

[1] Abaidoo, N. \& Arkorful, V. (2015) "The role of e-learning, advantages and disadvantages of its adoption in higher education." International Journal of Instructional Technology and Distance Learning. Volume 12 No. 1 Available at: http://www.itdl.org/Journal/Jan 15/Jan15.pdf Accessed on the 27 April 2017.

[2] Barker, A., Krull, G. and Mallinson (2005). "A Proposed Theoretical Model for M-Learning Adoption in Developing Countries." Proceedings of m-Learn Conference. Available at: https://pdfs.semanticscholar.org/7766/1f9fcc6291271be7728a886e e62c3409a7ec.pdf Accessed on 27 April 2017.

[3] Bender, G. (2008). "Exploring conceptual models for community engagement at higher education institutions in South Africa" Perspectives in Education, Volume 26 No. 1. University of the Free State: Bloemfontein, South Africa. pp. 81-95

[4] Brown, TH. (2005) "Towards a model for m-learning in Africa." International Journal on E- learning. Volume 4 No. 3. pp. 299-315 AACE: Norfolk, United States of America.

[5] Damoense, M. (2003). "Online learning Implications for effective learning for higher education in South Africa." Australian Journal of Educational Technology. [A]scilite: Tugun, Australia. Volume 19 No.1. pp. 25-45

[6] Englebrecht, E. (2003). "A look at e-learning models: investigating their value for developing an e-learning strategy." South African Journal of Open and Distance Learning Practice. Progressio: Pretoria, South Africa. Volume 25 No. 2. pp.38-47

[7] Freudenberg, B., Brimble, M. and Cameron, C. (2011). "WIL and generic skill development: The development of business students' generic skills through work- integrated learning" Asia-Pacific Journal of Cooperative Education. APJCE: Hamilton, New Zealand. Volume 12 No. 2. pp. 79-93.

[8] Guiney, P. (2015) E-learning in the workplace: An Annotated bibliography. Ministry of Education: Wellington, New Zealand.

[9] Hatcher, J. and Erasmus, N. (2008). "Service-Learning in the United States and South Africa: A Comparative Analysis Informed by John Dewey and Julius Nyerere." Michigan Journal of Community Service Learning. University of Michigan: Michigan, Unites States of America. Volume 1 No 3. pp.49-61.

[10] Jackson, D. (2013) "Employability skill development in workintegrated learning: Barriers and best practice." Studies in Higher Education, pp 1-18.Available at: http://ro.ecu.edu.au/ecuworks2013/666 Accessed on the 27 April 2017.

[11] Morris, M., Bessant, J. and Barnes, J. (2006). "Using learning networks to enable industrial development." International Journal of Operations \& Production Management. Emerald Group Publishing Limited: Bingley, United Kingdom. Volume 26 No. 25. pp. 532-557.

[12] Overton, L. \& Hills, H. (2009). E-learning maturity in the workplace - the benefits and practices. Impact: Journal of Applied Research in Workplace E-learning, 1(1), 113-136.

[13] Senge, P, et al. (1999). The Dance of Change: The Challenges to Sustaining Momentum in Learning Organizations. Doubleday: New York, United States of America.

[14] Sife, A., Lwoga, E., \& Sanga, C. (2007). "New technologies for teaching and learning: Challenges for higher learning institutions in developing countries." International Journal of Education and Development using ICT . Univeristy of the West Indies: Bridgetwon, Barbados. Volume 3 No. 2. Available at: http://ijedict.dec.uwi.edu/viewarticle.php?id=246\&layout=html Accessed on 27 April 2017. 
[15] Wains, S.I. and Mahmood, W. (2008). "Integrating M-Learning with E-Learning." Proceedings of SIGITE'08 Conference. Available https://pdfs.semanticscholar.org/cf94/51f8999dd9a98c7b163497ff7 74c9e1376c0.pdf Accessed on 27 April 2017.N.,

\section{AUTHORS}

Lize Moldenhauer works in the field of Adult and Vocational Learning in South Africa. She is the Managing Director of OMNI HR Consulting and the CEO for the SC Training Company. She has studied in the fields of Occupationally Directed Education, Training and Development Practices and her research interests include
Contact Centre Management, Human Resources, elearning practices and occupational learning.

Cindy Londt works in the field of Adult and Vocational Learning in South Africa. She is the Operations Executive for OMNI HR Consulting, and has studied in the fields of Occupationally Directed Education, Training and Development Practices. Her research interests include Operations in Education, Training and Development, Contact Centre Operations, Project Management and elearning practices. cindy@omnihrc.com

Article submitted 03 July 2018. Final acceptance 31 October 2018. Final version published as submitted by the authors. 